\title{
SEX, LIES AND DISCLOSURES: RESEARCHERS AND THE REPORTING OF UNDER-AGE SEX
}

\author{
Ann Strode, $B A L L B, L L M$ \\ Faculty of Law, University of KwaZulu-Natal, Pietermaritzburg \\ Catherine Slack, BA, MA Clin Psych \\ HIVIAIDS Vaccines Ethics Group, School of Psychology, University of KwaZulu-Natal, Pietermaritzburg
}

\begin{abstract}
Children (persons under 18) are a vulnerable group and require legal protection because of their youth and inexperience. ${ }^{1}$ As a result, various provisions in the law ensure the care and protection of children through mechanisms such as mandatory reporting obligations, which generally require persons in positions of authority, in special relationships with children or even strangers to report to the authorities when a child is in need of care and protection. ${ }^{2}$ Within this context, a recent change in the law has placed an obligation on any person who is aware of a sexual offence having been committed against a child to report this to the police in terms of the Criminal Law (Sexual Offences and Related Matters) Amendment Act, hereafter referred to as the 'Sexual Offences Act.'. Given that it is an offence in terms of this Act to have sex below the age of 16, researchers involved in research with teenage participants in the course of which they may become aware that participants are engaging in sex or sexual activity but are under the age of 16 will be obliged to inform the police of this fact.
\end{abstract}

This article describes the changes introduced by the Sexual Offences Act and the implications it poses for the research relationship. It proposes non-compliance with certain provisions in this Act when specific conditions are met, and concludes with recommendations for advocacy against inappropriate and senseless reporting of consensual under-age sex or sexual activity.

\section{OVERVIEW OF THE SEXUAL OFFENCES ACT}

On 16 December 2007 parts of the new Sexual Offences Act came into operation. Among other things the Act aims to address the vulnerability of children (persons under 18) to sexual abuse or exploitation by enacting a number of new, expanded or amended provisions. It provides among others that:

- A male or female under the age of 12 years is incapable of consenting to a sexual act (section 57(1)).

- The age of consent to sexual penetration and other related sexual activities is 16 (s 15 and 16).

- If anyone engages in consensual sexual activity (which includes penetration) with a child between the ages of 12 and 16, they are both committing the crime of statutory rape.

- If anyone engages in consensual sexual activity (which includes non-penetrative direct or indirect contact with the genital organs or mouth) with a child between the ages of 12 and 16, they have both committed the crime of statutory sexual assault (s 16).

- Sexual exploitation of children, with or without their consent, is an offence. This can occur when a person unlawfully uses a child as a sex worker (s 17(1)). It is also an offence to facilitate the involvement of a child in sex work and to live off the earnings of a child involved in sex work (s 17(2) and (5)).

- Children may not be involved in or exposed to child pornography (s 19).

- It is an offence to compel children to witness various sexual acts or offences (s 21).

- It is an offence to 'flash' or expose certain body parts to children (s 22).

This Act also creates a broad obligation to report any sexual offence involving a child. Section 54(1) places this duty on 'any person' to report this information 'immediately' to a police officer. The duty comes into operation once the person is 'aware' of a sexual offence involving a child. The Oxford Dictionary defines awareness as 'having knowledge', so any person with information that any of the child sexual offences described in the Act have been committed is obliged to report this to the police. Any person failing to comply with this obligation commits an offence and may be sentenced to a fine or a maximum of 5 years in prison or both (s 54(1)(b)). 
IMPLICATIONS AND RECOMMENDATIONS

In many instances researchers may become aware through biomedical or social science research that an adolescent is involved in a sexual offence because they will have knowledge of a child's sexual activity - this may be because they ask adolescents questions about their sexual activity, identify sexually transmitted diseases or provide HIV testing services or access to contraceptives. Many of these adolescents will be between the ages of 12 and 16. Through these interactions researchers may well gain knowledge of a sexual offence that has been committed against or by a child.

The issue of reporting under-age sex is very complex, as in our view there are various categories of under-age sex. The first is under-age sex that is non-consensual, for example an adolescent of any age who has been raped. The second is under-age sex that is 'consensual' but could be regarded as abusive or exploitative, for example, a 15-year-old having sex with an 35-yearold for air time. The third is under-age sex and sexual activity that is 'consensual' and non-exploitative, for example, two 15-year-olds in a peer relationship.

Accordingly, we argue that under-age sex and sexual activity that is 'consensual' and non-exploitative should be treated differently from the first two categories. We submit that researchers should not report consensual, non-exploitative under-age sex or activities to the police. This approach requires researchers and research ethics committees to agree to not apply one portion of the Sexual Offences Act, and opens researchers to the possibility of being charged with violating the Act.

However, we argue that reporting consensual non-exploitative underage sex is in direct conflict with the principles articulated in the Children's Act, ${ }^{4}$ which expressly allows children under the age of 16 to access services such as contraceptive advice and methods, HIV testing, and medical treatment - the underlying principle being that they ought to be drawn into the service system and not excluded from it by the paternalistic approach of the criminal law.

Our approach is in line with the rights provided for in the Children's Act, which recognises the emerging autonomy of children by giving them the right to access to information on health promotion and the prevention and treatment of ill-health/diseases (s 13), to confidentiality regarding their health status provided this is in their best interests (s 13), to consent independently to HIV testing from the age of 12 (s 130) and to access contraceptives independently, and to confidentiality in this regard from the age of 12 (s 134). This approach can also be defended on the ethical grounds that harmful activities (non-consensual or exploitative) are reported, but that non-harmful activities (consensual and non-exploitative) are not reported because this is unlikely to protect children, may erode trust in adult or authority figures, and may decrease the veracity of disclosures children make to research staff - impeding the ability to steer them to appropriate services. Furthermore, the Sexual Offences Act itself seems to imply that where under-age sex is not exploitative prosecutions are only to be instituted in exceptional circumstances. Section 15(2)(a) states that where both children were under the age of 16 at the time of the alleged offence prosecutions are only to be instituted if authorisation has been obtained from the National Director of Public Prosecutions.

If this approach is considered to be unworkable because, for instance, researchers are vulnerable to being charged with being in contravention of the Sexual Offences Act, then researchers could consider reporting all sexual offences, including instances of consensual non-exploitative sexual activity. In this case, there could be either formalistic of full compliance with the law. If researchers opt for formalistic compliance they could do this through submitting a monthly sheet of names of adolescents having committed the sexual offences of consensual sex or sexual activity under the age of 16 with a member of their peer group, using a brief form. This could be sent to their closest police station. This form could contain the names of the adolescents but not other details, thus to some extent protecting the relationship between participant and researcher. Alternatively, there could be full compliance with the law by providing the police with all details of the under-age sex including the names and addresses of the participants.

We think both approaches have disadvantages because they may: (i) baffle community groups being mobilised for the research; (ii) impact on the scientific validity of the data the research is collecting, as adolescents may be less truthful; (iii) impact on enrolment practices, perhaps skewing enrolment towards a certain category of adolescent, affecting the generalisability of the data; (iv) increase risks of social harms for adolescents (like stigma); ( $v$ ) be difficult to explain to adolescents and parents in the consent process; ( $v i)$ represent a threat to confidentiality as, in small communities, adolescents may be known to the police, and the protection of the list once in the hands of the police cannot be guaranteed; and (vii) erode beneficial aspects of the research such as steering adolescents in need to the appropriate services.

\section{CONCLUSIONS}

We argue that researchers should not comply with the mandatory reporting obligations for under-age consensual, non-exploitative sexual activity on the carefully considered grounds described above. 
In all other cases there should be reporting, even of sex or sexual activity that is described as consensual by the adolescent, but appears exploitative in nature.

This approach may actually require researchers to work harder than if they merely followed the letter of the law, by requiring them to assess the consensual, nonexploitative nature of the sexual activity, intervene in various ways to assist children, and design consent forms and processes with enough detail to enable parents and children to fully understand when reporting of sexual activity will occur.
We argue that because mandatory reporting of underage sex/sexual activity (even consensual and non-exploitative activity) may alienate children from services and 'punish' them by reporting their conduct to the police, advocacy is needed for a change to the Sexual Offences Act to ensure consistency with the approach taken in the Children's Act.

\section{REFERENCES}

1. Kruger JM, Robinson JA. The legal status of children and young persons. In: Robinson JA, ed. The Law of Children and Young Persons. Durban: Butterworths, 1997: 1-48.

2. South African Law Reform Commission. Report on the Review of the Child Care Act (2002). http://www.doj.gov.za/salrc/reports/r_prj110_childcare/r_pr110_ cont_2002dec.pdf (accessed 20 May 2009).

3. Act No. 32 of 2007

4. Act No. 38 of 2005 .

\section{Erratum}

In the article entitled 'The ghost of AIDS denialism: Manguzi Hospital and dual loyalty', which appeared in the third issue of this journal last year, there was an error in order of authorship. The first author should have been Donna Knapp van Bogaert, and the correct citation is as follows: Donna Knapp van Bogaert, Marlise Richter. The ghost of AIDS denialism: Manguzi Hospital and dual loyalty. Southern African Journal of HIV Medicine 2008; 9(3): 8-12, 14.

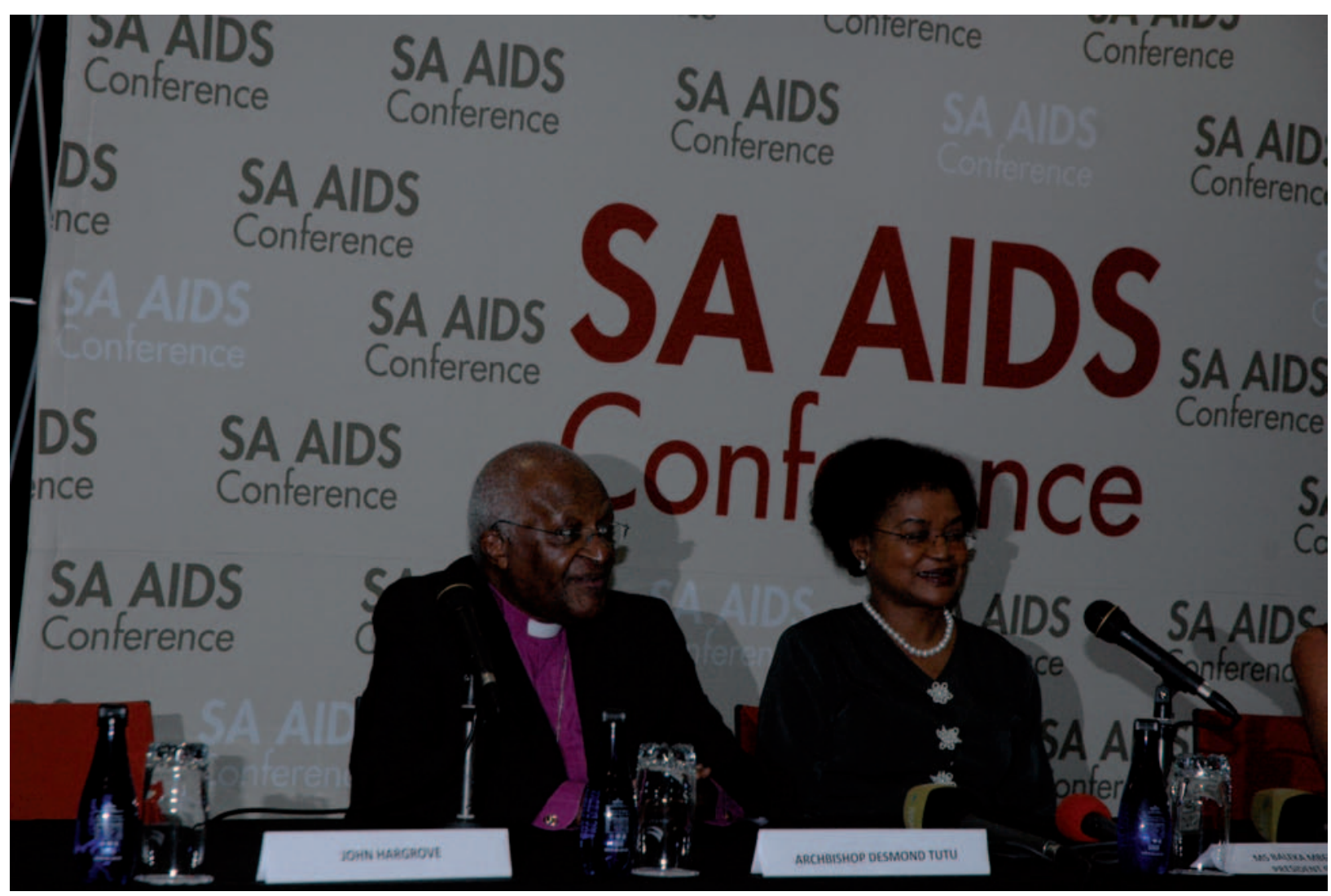

